\title{
Effect of Inter-Repetition Rest vs. Traditional Strength Training on Lower Body Strength, Rate of Force Development, and Muscle Architecture
}

\author{
Nikolaos Zaras ${ }^{1,2, *}$, Angeliki-Nikoletta Stasinaki ${ }^{2}$, Polyxeni Spiliopoulou ${ }^{2}$, Thomas Mpampoulis ${ }^{2}$, \\ Marios Hadjicharalambous ${ }^{1}$ (D) and Gerasimos Terzis ${ }^{2}$ (I) \\ 1 Human Performance Laboratory, Department of Life and Health Sciences, University of Nicosia, \\ Nicosia 24005, Cyprus; hadjicharalambous.m@unic.ac.cy \\ 2 Sports Performance Laboratory, School of Physical Education and Sport Science, National and Kapodistrian \\ University of Athens, 17237 Athens, Greece; agstasin@phed.uoa.gr (A.-N.S.); spipolyxeni@phed.uoa.gr (P.S.); \\ thompamp@phed.uoa.gr (T.M.); gterzis@phed.uoa.gr (G.T.) \\ * Correspondence: zaras.n@unic.ac.cy; Tel.: +357-22842318; Fax: +357-22842399
}

Citation: Zaras, N.; Stasinaki, A.; Spiliopoulou, P.; Mpampoulis, T.; Hadjicharalambous, M.; Terzis, G. Effect of Inter-Repetition Rest vs. Traditional Strength Training on Lower Body Strength, Rate of Force Development, and Muscle Architecture. Appl. Sci. 2021, 11, 45. https://dx.doi.org/10.3390/ app11010045

Received: 5 December 2020

Accepted: 21 December 2020

Published: 23 December 2020

Publisher's Note: MDPI stays neutral with regard to jurisdictional claims in published maps and institutional affiliations.

Copyright: () 2020 by the authors. Licensee MDPI, Basel, Switzerland. This article is an open access article distributed under the terms and conditions of the Creative Commons Attribution (CC BY) license (https: / / creativecommons.org/ licenses/by/4.0/).

\begin{abstract}
The purpose of the study was to investigate the effect of seven weeks inter-repetition rest vs. traditional strength training on lower body strength, rate of force development (RFD), and vastus lateralis (VL) muscle architecture. Sixteen male participants were assigned into two groups: the interrepetition rest (IRRG) and the traditional (TG) group. Both groups performed the leg press exercise with four sets of six maximum repetitions (RM) for two training sessions per week. IRRG added a $20 \mathrm{~s}$ inter-repetition rest period between single repetitions. Before and after the training period, 1-RM in leg press, isometric leg press RFD, and peak force (PF), VL muscle architecture, vastus intermedius (VI) thickness, and quadriceps' cross sectional area (CSA) with ultrasonography, were measured. Two way ANOVA for repeated measures was used for statistics. One-RM strength increased similarly for both groups $(p<0.05)$, while percentage increases in RFD were greater for IRRG compared to TG $(p<0.05)$. Isometric PF was increased similarly for both groups $(p<0.05)$. VL and VI thickness as well as CSA of the quadriceps increased similarly in both groups, while VL fascicle length increased more following IRRG compared to TG (IRRG: $4.8 \pm 6.1 \%$ vs. TG: $-3.9 \pm 5.4 \%, p=0.001$ ). These results suggest that $20 \mathrm{~s}$ inter-repetition rest during strength training may effectively increase lower body explosive strength and muscle fascicle length without compromising muscle hypertrophy.
\end{abstract}

Keywords: resistance training; fascicle length; lower body explosiveness; skeletal muscle hypertrophy

\section{Introduction}

Traditional resistance training is the most effective stimulus for increasing muscle mass and strength in individuals of all ages and training background [1,2]. Traditionally, resistance exercise is performed by lifting an external resistance for a number of repetitions which are completed consecutively, with no rest between each repetition, while a rest period of a few seconds/minutes follows after this set of repetitions. This training method results in a temporal decrease in muscle power output and movement velocity mainly due to phosphocreatine (PCr) depletion and lactate accumulation in exercised muscle cells [3,4], while other factors also contribute to muscle fatigue, such as high ammonia concentration and reduced neural activation [5,6]. In contrast to this traditional resistance exercise paradigm, introduction of short rest periods implemented between single repetitions (inter-repetition rest: IRR), or between groups of repetitions (cluster sets) has been proposed as an alternative effective way to increase muscle strength and mass [7]. The rest between repetitions may be between 15 and $40 \mathrm{~s}$, depending on the training goal, i.e., hypertrophy, maximum strength, or power [8], while cluster set structure may include double or triple repetitions, either increasing the total training rest of re-distributing the 
total rest period between repetitions and sets [7]. Acute and long-term training studies revealed that inter-repetition rest may result in faster resynthesis of adenosine triphosphate (ATP), lower blood lactate concentration, and an increase in the repetition velocity compared to traditional training $[4,9,10]$. In addition, inter-repetition rest has been reported to increase the total training volume and intensity compared to traditional resistance training [11-13], resulting in greater improvement in muscle strength [4,14]. However, other studies favored traditional resistance training to increase muscle strength $[15,16]$, while in one study, similar increase in maximum strength was reported after inter-repetition rest and traditional resistance training with equated rest periods between training programs [17]. These ambiguous results may be due to the different training background of the participants, the acquired training experience and/or the concurrent resistance training of other body parts leading to divergent neural adaptations and as a consequence different strength outcomes [18]. Thus, whether inter-repetition rest training is superior in strength improvements or not to traditional resistance training remains largely unresolved.

The rate of force development (RFD) characterizes the ability of the neuromuscular system to produce force rapidly in limited time frames, usually during the initial $250 \mathrm{~ms}$ after contraction initiation [19]. Traditional resistance training increases RFD, even after short training periods ( $<6$ weeks) [20]. Moreover, the intention to perform each repetition with high velocity, regardless of the external load used, is of great importance to increase RFD with traditional resistance training [20-22]. Some data support that cluster training enhances power and velocity to a greater extent than traditional strength training $[3,23]$. Since inter-repetition rest training allows an increased repetition velocity compared to traditional training $[9,10]$, it might result in increased explosive performance; however, to the best of the authors' knowledge, the effect of inter-repetition rest sets configuration on RFD has not been investigated yet.

The architectural characteristics of the muscles, namely muscle thickness, fascicle angle and fascicle length, have been associated with muscle strength, muscle power and RFD [21,24-26]. Traditional resistance training induces significant changes in muscle architecture by increasing mainly the muscle thickness and fascicle angle [27,28]. Fascicle length seems to remain largely unaltered in response to traditional resistance training, but it seems to increase with fast eccentric and power training [21,26,29-31]. Nevertheless, the effect of cluster resistance training on muscle architecture has not been investigated. Cluster resistance training seems to favor lower body muscle power with changes in fascicle length as one of the possible underlying mechanisms, which may also apply for inter-repetition rest. Therefore, the purpose of the present study was to investigate the effect of inter-repetition rest versus traditional resistance training on lower body maximum strength, RFD and muscle architecture. It was hypothesized that inter-repetition rest resistance training would induce greater increases in lower body muscle strength and RFD compared to traditional training.

\section{Materials and Methods}

\subsection{Experimental Design}

A repeated measures design was used to investigate the effects of IRR vs. traditional resistance training on muscle strength, RFD and muscle architecture in a group of male physical education students (Figure 1). Sixteen participants were assigned according to their initial 1 repetition maximum (1-RM) strength in leg press, so that the two groups have similar initial strength, into either an inter-repetition rest group (IRRG) or a traditional group (TG) and followed 7 weeks of resistance training using a $45^{\circ}$ incline leg press. Before the training intervention period, participants visited the laboratory on three different occasions separated by $48 \mathrm{~h}$. During the first visit, measurement of leg-press 1 repetition maximum (1-RM) strength was performed as well as familiarization with the RFD measurement. Isometric leg press RFD and isometric peak force (PF) were evaluated in the second visit and vastus lateralis (VL) muscle architecture, vastus intermidius (VI) muscle 
thickness, and quadriceps cross sectional area (CSA) via ultrasonography on the third visit. Measurements were performed in the same order after the training intervention.

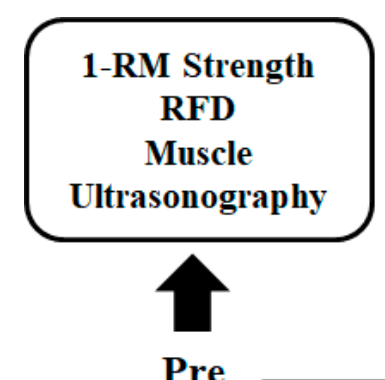

Measurements

\section{Week Training Period 2 Training Sessions per Week}

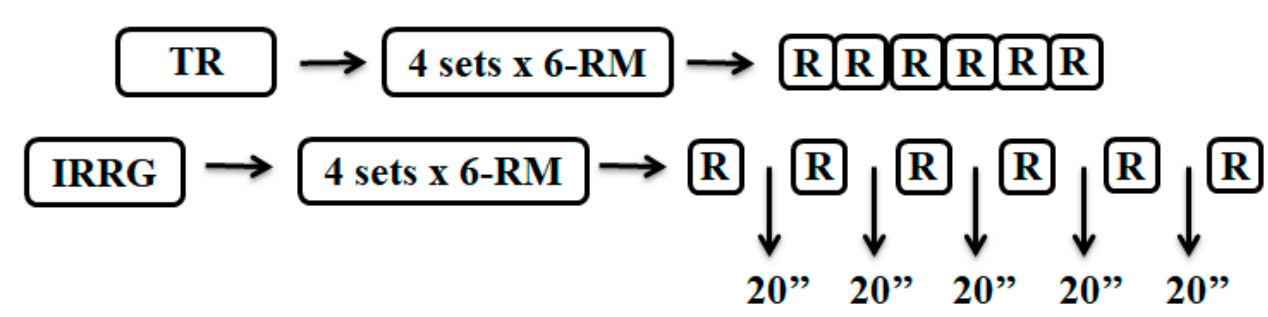

Figure 1. Training design for inter-repetition rest group (IRRG) and traditional group (TG). Both groups trained with 4 sets of 6 repetitions but IRRG added 20 s rest between repetitions. Rest between sets was 3 min for both groups. 1-RM = one repetition maximum, $\mathrm{RFD}=$ rate of force development, $\mathrm{R}=$ Repetition.

\subsection{Subjects}

Twenty male physical education students were initially recruited and informed about the purpose of the study and the experimental procedures. They signed an institutionally approved informed consent before entering in the research procedure. Four participants withdraw during the initial familiarization sessions, for purposes unrelated to the study. Thus, 16 participants were assigned into two groups, the inter-repetition rest group (IRRG: $\mathrm{N}=8$, age: $23.6 \pm 6.8$ years, body mass: $75.7 \pm 8.4 \mathrm{~kg}$, body height: $1.80 \pm 0.07 \mathrm{~m}$ ) and the traditional group (TG: $\mathrm{N}=8$, age: $21.7 \pm 2.7$ years, body mass: $79.5 \pm 12.8 \mathrm{~kg}$, body height: $1.79 \pm 0.08 \mathrm{~m}$ ), Participants were allocated into the two training groups, according to their initial leg press 1-RM strength. More specific, following the initial 1-RM leg press strength measurement (for details see below) participants were assigned into the (IRRG: $237.5 \pm 30.5 \mathrm{~kg}$ or TG: $261.3 \pm 26.6 \mathrm{~kg}$. A T-Test statistical analysis revealed no significant difference between groups (IRRG: $237.5 \pm 30.5 \mathrm{~kg}$ vs. TG: $261.3 \pm 26.6 \mathrm{~kg}, p=0.120$ ). Participants fulfilled the following criteria: (a) absence of any orthopedic/neuromuscular maladies, (b) absence of drug abuse or nutritional supplements, and (c) absence of systematic resistance exercise training at least during the previous 6 months. All participants followed the same courses during the study semester, including studying the tactics of team sports, approximately $3 \mathrm{~h}$ per week, according to their academic program of the University. None of them followed systematic sport activity outside of the University program. All procedures were in accordance with the 1975 Declaration of Helsinki as revised in 2000 and were approved by the Institutional Ethics Committee (project number 1024/8/11/2017).

\subsection{Procedures}

\subsubsection{Training}

Training was performed for 7 weeks, 2 times per week with at least $72 \mathrm{~h}$ rest between training sessions. The TG performed 4 sets of 6 repetitions with $85 \%$ of $1-\mathrm{RM}$, with a 3-min rest interval between sets. When a TG participant performed more than 6 repetitions in a set the load was increased in the following set to meet the 6-RM. The new (increased) load was 
also used for the initial set of the following training session. Participants of the IRRG also performed 4 sets of 6 repetitions with $85 \%$ of 1-RM with 3 min rest between sets. However, the IRRG training included $20 \mathrm{~s}$ rest between single repetitions $[9,32]$. Single repetitions were selected because of the previously reported positive effect on muscle strength [4] During the 20-s rest between repetitions, the load was locked in the rack of the leg press machine and the participant remained seated with feet placed on the floor (not on the leg press platform). Five seconds before the end of the 20-s rest period, participants placed their feet on the leg press platform and performed the next repetition in response to the researcher instruction (precisely at $20 \mathrm{~s}$ ). At all training sessions and repetitions two researchers assisted the participants in order to take off the load from the rack. This was performed because the load was locked in a lower position where the knees were bended approximately at $75-85^{\circ}$. Thus, in order to avoid any unnecessary fatigue and injuries starting from this position all participants received assistance to unlock the loads. Given the advantage of inter-repetition rest training on achieving a high movement velocity in each repetition, participants were not specifically instructed to perform the training with maximum intended movement velocity. The total training session duration for the IRRG was $39.3 \pm 1.4 \mathrm{~min}$ and for TG was $36.9 \pm 0.9 \min \left(p=0.001, \eta^{2}=0.176\right)$.

Thirty minutes after the end of every training session, participants provided their rating of perceived exertion 1-10 scale score (RPE) [33], for the evaluation of the training intensity. An RPE score lower or equal to 7 (very hard range), signified a $2.5 \%$ load increase for the next training session for the IRRG [34,35]. By the end of the current training intervention program, no significant difference was observed in mean session RPE (IRRG: $7.8 \pm 0.3$ vs. TG: $8.1 \pm 0.3, p=0.419, \eta^{2}=0.047$, Figure 2) and in mean total training volume (IRRG: $5090.1 \pm 566.2 \mathrm{~kg}$ vs. TG: $5532.5 \pm 451.4 \mathrm{~kg}, p=0.106, \eta^{2}=0.176$, Figure 3), between IRRG and TG.

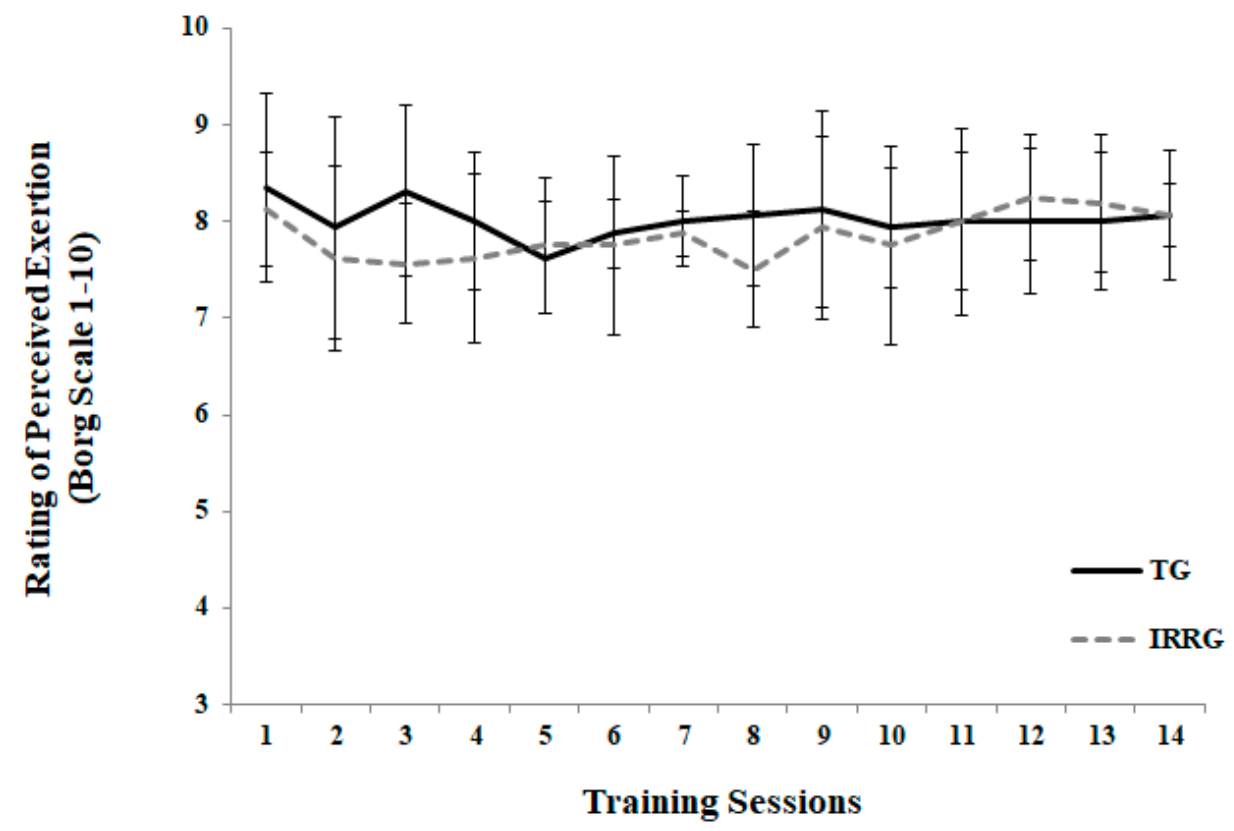

Figure 2. The rating of perceived exertion during 7 weeks resistance training for Traditional group (TG, black line) and Inter-repetition rest group (IRRT, grey dashes). No significant differences were found between groups $(p>0.05)$. 


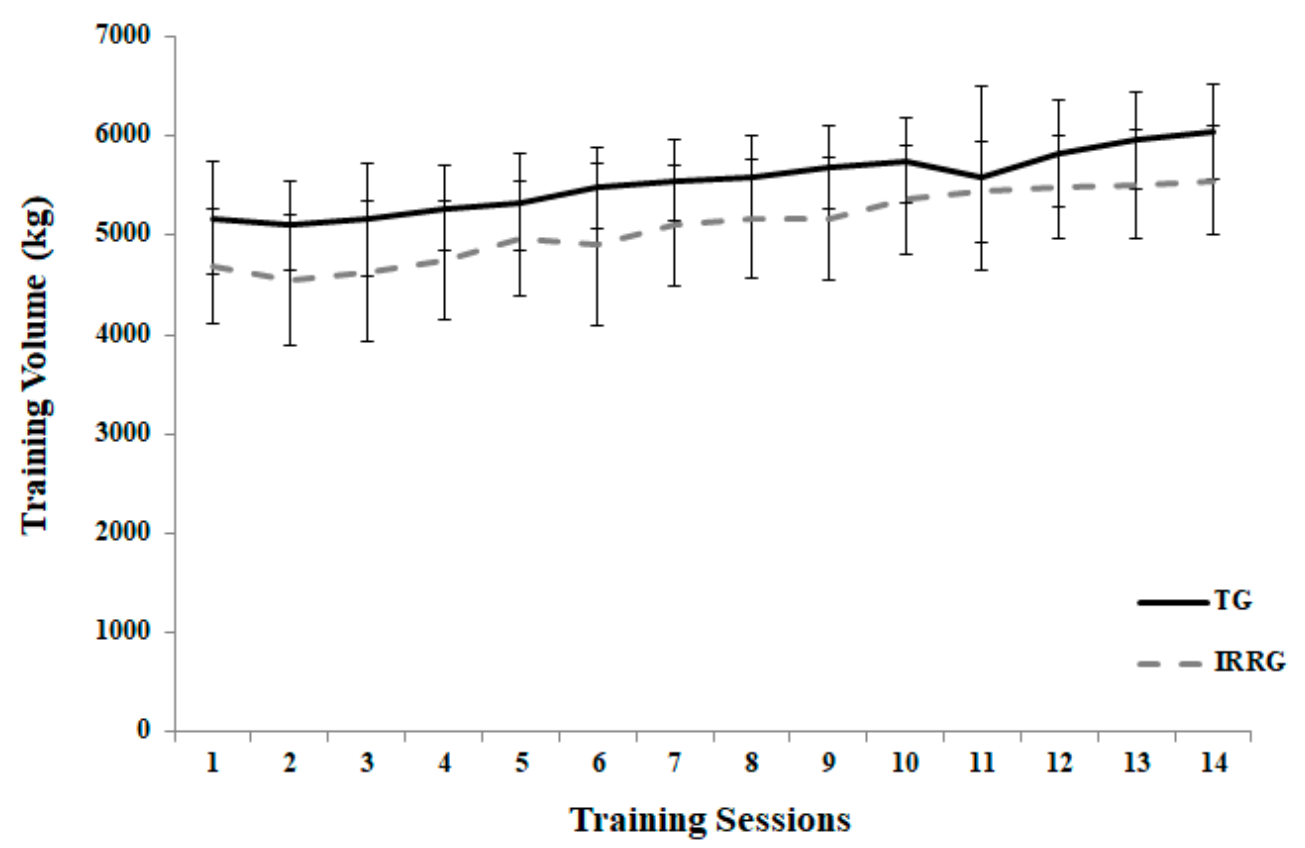

Figure 3. Changes in training volume during the 7 weeks resistance training for Traditional group (TG, black line) and Inter-repetition rest group (IRRG, grey dashes). No significant difference were found between groups $(p>0.05)$.

\subsubsection{Leg Press 1-RM Strength}

Maximum leg press strength was performed in a $45^{\circ}$ incline leg press machine. After a 10-min warm-up on a stationary bicycle and static and dynamic stretching exercises for the major muscle groups, participants performed 2 sets of 10 repetitions with $80 \mathrm{~kg}$ in order to warm up. Then, 3 sets of 8,6 and 4 repetitions with approximately $50-60 \%$, $70-75 \%$, and $80-85 \%$, respectively, of the predicted 1-RM were allowed. Then, $3-5$ sets of 1 repetition were performed in order to determine the maximum strength. Three minutes of rest was allowed between sets while two of the researchers were present for monitoring the execution technique of the exercise and encouraging participants to perform their maximum strength. The intra-class correlation coefficient (ICC) for 1-RM leg press strength measurement was 0.98 (95\% confidence intervals (CI) with lower and upper bounds: $0.940-0.990$, coefficient of variation (CV\%) was $8.1 \%)$.

\subsubsection{Leg Press Isometric Peak Force and Rate of Force Development}

Participants started with five minutes warm-up on a stationary bicycle followed by static and dynamic stretching exercises for lower body muscles. Then, participants seated on a custom-made steel leg press chair and placed both feet on a force platform (Applied Measurements Ltd. Co., Reading, UK; WP800, A/D sampling frequency $1 \mathrm{kHz}$ ), which was positioned vertical to the laboratory wall. Knee angle was set at $120^{\circ}$ and hip angle at $100^{\circ}[25,36]$. A real-time visual feedback of the force applied was provided for each effort via a computer monitor placed just above the force platform in front of the participants. Two attempts were allowed with progressively increasing forces followed by two explosive attempts with approximately $80 \%$ of the individual perceived maximum strength. Subsequently, three maximum efforts were performed with $3 \mathrm{~s}$ duration and with $3 \mathrm{~min}$ rest between them. Participants were instructed to apply their maximum force as fast as possible while verbally encouraged to perform their best effort. Data from the force platform were recorded (Kyowa sensor interface PCD-320A) and analyzed. Variables calculated from the force-time curve included the maximum isometric PF which was the greatest force generated from the force-time curve and the RFD in specific time windows of $0-30,0-50,0-80,0-100,0-150,0-200$, and $0-250 \mathrm{~ms}$, relative to the onset of contraction, which was set at $2.5 \%$ of the difference between baseline and maximum 
force [37]. The ICCs for the leg press RFD during repeated trials were $\mathrm{RFD}_{30 \mathrm{~ms}}=0.92$ (95\% CI: 0.095-0.989, CV = 33.4\%), RFD ${ }_{50 \mathrm{~ms}}=0.96$ (95\% CI: $0.385-0.994, \mathrm{CV}=32.4 \%$ ), $\mathrm{RFD}_{80 \mathrm{~ms}}=0.818$ (95\% CI: $\left.0.818-0.995, \mathrm{CV}=27.5 \%\right), \mathrm{RFD}_{100 \mathrm{~ms}}=0.98$ (95\% CI: $0.890-0.996$, $\mathrm{CV}=23.9 \%), \mathrm{RFD}_{150 \mathrm{~ms}}=0.98$ (95\% CI: $\left.0.940-0.998, \mathrm{CV}=18.1 \%\right), \mathrm{RFD}_{200 \mathrm{~ms}}=0.98(95 \% \mathrm{CI}$ : $0.871-0.996, \mathrm{CV}=14.7 \%)$ and $\mathrm{RFD}_{250 \mathrm{~ms}}=0.97(95 \% \mathrm{CI}: 0.778-0.995, \mathrm{CV}=12.1 \%)$. The ICC for maximum isometric PF was 0.98 (95\% CI: 0.903-0.996, CV = 9.6\%).

\subsubsection{Muscle Ultrasonography}

Real-time B-mode ultrasonography (Mindray Z5, Bio-Medical Electronics Co., Ltd., Shenzhen, China) was used to measure VL muscle thickness, fascicle angle, fascicle length and VI thickness. All measurements were performed during the morning hours and all participants rested in the supine position for $15 \mathrm{~min}$ before all measurements. Ultrasound images were obtained at $40 \%$ of the distance from the central palpable point of the greater trochanter to the lateral condyle of the femur [38] of the non-dominant leg. A $38 \mathrm{~mm}$ long, $10 \mathrm{MHz}$ linear-array probe was used to obtain a single view (extended field of view) from $\sim 40 \mathrm{~mm}$ before, to $\sim 40 \mathrm{~mm}$ after the marked point $[25,39]$. In order to ensure the clarity of the images and the whole length of the fascicles, probe was coated with sufficient waterarray transmission gel and moved properly along the fascicles path [40]. Two images were taken for each participant, analyzed by an image analysis software (Motic Images Plus, 2.0, Hong Kong) and the mean value of each parameter was used for statistical analysis. The ICC for VL muscle thickness, fascicle angle, and fascicle length was 0.970 (95\% CI: 0.856-0.987, CV $=10.4 \%$ ), 0.880 (95\% CI: $0.609-0.965, \mathrm{CV}=7.3 \%$ ), and 0.840 (95\% CI: $0.470-0.955, \mathrm{CV}=9.7 \%)$, respectively. In addition the ICC for VI muscle thickness was 0.928 (95\% CI: $0.799-0.975, \mathrm{CV}=15.5 \%$ ).

Quadriceps CSA measurement was performed at $40 \%$ of the distance between the center of the patella and the medial aspect of the anterior superior iliac spine (proximal to the knee) of the non-dominant leg. A perpendicular guide-line was drawn with an indelible marker, so that probe was moved transversely across the thigh. Using the extended-field-of-view mode, every image pictured the CSA of each of the four heads separately [41]. The CSA of each head (vastus lateralis-VL, rectus femoris-RF, vastus intermedius-VI, vastus medialis-VM) was assessed with an image analysis software (Motic Images Plus, 2.0, Hong Kong). The CSA of whole quadriceps femoris was the sum of the four heads. Two images were taken for each participant and the mean values were used for statistical analysis. The ICC for CSA of VL, RF, VI, VM and whole Quad was 0.962 (95\% CI: $0.835-0.991, C V=15.2 \%), 0.949$ (95\% CI: $0.725-0.989, \mathrm{CV}=20.1 \%$ ), 0.956 (95\% CI: $0.814-0.99, \mathrm{CV}=19.7 \%), 0.872$ (95\% CI: $0.479-0.971, \mathrm{CV}=20.2 \%)$, and 0.974 (95\% CI: 0.892-0.994, CV = 16.2\%), respectively. All ultrasound images after the training period were obtained $48 \mathrm{~h}$ after the last training session.

\subsection{Statistical Analysis}

All data are presented as mean $\pm \mathrm{SD}$. A 2-way repeated measures analysis of variance $(2 \times 2$ group $\times$ time), with Bonferroni post hoc correction, were used to evaluate differences for each variable between groups. Calculation of effect sizes $\left(\eta^{2}\right)$ was also performed. Repeated measures analysis of covariance (ANCOVA) was used for RFD performance test because significant differences were found between IRRG and TG groups at pre-test measurements. Independent sample T-Test was used to detect changes in session RPE and training volume, between IRRG and TG, as well as to examine percentage differences in response to training between the IRRG and TG. Reliability for all measurements was performed using a two way random effect intra class correlation coefficient (ICC) with $95 \%$ confident intervals $(\mathrm{CI})$, as well as by calculating the coefficient of variation $(\mathrm{CV} \%)$. All data were analyzed using SPSS 21 , whilst, $p \leq 0.05$ was used as a 2-tailed level of significance. 


\section{Results}

No significant differences were found between groups during the pre-intervention measurement $(p \geq 0.05)$ except for leg press RFD (see below). Results for body mass, 1-RM strength, isometric RFD, and isometric PF are presented in Table 1. Body mass remained unaltered after IRRG $\left(p=0.120, \eta^{2}=0.160\right)$ and after TG $\left(p=0.556, \eta^{2}=0.025\right)$. Leg press 1 -RM was significantly increased after IRRG by $20.4 \pm 5.9 \%\left(p<0.001, \eta^{2}=0.814\right)$ and after TG by $20.4 \pm 10.8\left(p<0.001, \eta^{2}=0.835\right)$, while there was no significant difference between groups $\left(p=0.417, \eta^{2}=0.048\right)$. ANCOVA revealed that RFD remained unaltered after both IRRG and TG at all time frames of the force-time curve $(p>0.05)$. However, IRRG induced greater percentage increases during $30 \mathrm{~ms}, 50 \mathrm{~ms}$, and $80 \mathrm{~ms}$ compared to TG (RFD ${ }_{30 \mathrm{~ms}}$ IRRG: $43.6 \pm 56.8 \%$ vs. TG: $-3.3 \pm 14.5 \%, p=0.016, \eta^{2}=0.360$, RFD $_{50 \mathrm{~ms}}$ IRRG: $44.3 \pm 58.9 \%$ vs. TG: $-1.1 \pm 16.6 \%, p=0.023, \eta^{2}=0.323$, RFD $80 \mathrm{~ms}$ IRRG: $33.4 \pm 47.3 \%$ vs. TG: $\left.-5.9 \pm 15.1 \%, p=0.042, \eta^{2}=0.263\right)$. Isometric PF was significantly increased over-time following IRRG by $17.4 \pm 8.5 \%\left(p<0.001, \eta^{2}=0.638\right)$ and TG by $12.3 \pm 8.7 \%(p<0.001$, $\eta^{2}=0.547$, with no significant difference between groups.

Results from VL muscle architecture, VI thickness and CSA of quadriceps are presented in Table 2. VL muscle thickness was increased significantly over-time following TG (from $2.6 \pm 0.4 \mathrm{~cm}$ to $2.7 \pm 0.4 \mathrm{~cm}, p=0.043, \eta^{2}=0.262$ ), as well as after IRRG (from $2.5 \pm 0.3 \mathrm{~cm}$ to $2.6 \pm 0.2 \mathrm{~cm}, p=0.048, \eta 2=0.260)$. VL fascicle angle remained unchanged after IRRG ( $\left.p=0.983, \eta^{2}=0.000\right)$ and TG $\left(p=0.366, \eta^{2}=0.059\right)$; however, VL fascicle length increased only after IRRG from $8.3 \pm 0.9 \mathrm{~cm}$ to $8.7 \pm 1.1 \mathrm{~cm}\left(p=0.044, \eta^{2}=0.260\right)$ and the percentage increase was significant greater compared to TG (IRRG: $4.8 \pm 6.1 \%$ vs. TG: $\left.-3.9 \pm 5.4 \%, p=0.009, \eta^{2}=0.393\right)$. VI muscle thickness remained unaltered after IRRG $\left(p=0.442, \eta^{2}=0.043\right)$ and TG $\left(p=0.813, \eta^{2}=0.004\right)$. When VL and VI muscle thickness were combined, significant increase was found for IRRG $\left(3.8 \pm 3.0 \%, p=0.010, \eta^{2}=0.387\right)$ and TG $\left(3.2 \pm 4.0 \%, p=0.013, \eta^{2}=0.365\right)$, with no difference between groups $(p=0.330$, $\left.\eta^{2}=0.068\right)$.

Total quadriceps CSA was increased significantly after IRRG $(14.3 \pm 9.5 \%, p<0.001$, $\left.\eta^{2}=0.611\right)$ and TG $\left(12.5 \pm 7.6 \%, p=0.002, \eta^{2}=0.512\right)$, with no significant difference between groups $\left(p=0.690, \eta^{2}=0.012\right)$. In addition, both groups increased VL CSA $\left(23.4 \pm 17.9 \%, p<0.001, \eta^{2}=0.599\right.$ and $16.7 \pm 12.7 \%, p=0.004, \eta^{2}=0.458$, for IRRG and TG, respectively) and VI CSA $\left(15.7 \pm 9.6 \%, p<0.001, \eta^{2}=0.548\right.$ and $12.1 \pm 9.6 \%, p=0.013$, $\eta^{2}=0.367$, for IRRG and TG, respectively), but only TG increased VM CSA by $19.7 \pm 11.5 \%$ $\left(p=0.003, \eta^{2}=0.468\right)$. No significant change was observed for the CSA of RF for any of the groups. 
Table 1. Changes in body mass, leg press 1-RM strength, rate of force development, and isometric peak force after 7 weeks of inter-repetition rest or traditional resistance training.

\begin{tabular}{|c|c|c|c|c|c|c|c|c|c|c|c|c|}
\hline \multirow[b]{2}{*}{ Measurement } & \multicolumn{5}{|c|}{ Traditional Group } & \multicolumn{5}{|c|}{ Inter-Repetition Rest Group } & \multicolumn{2}{|c|}{$\begin{array}{c}\% \text { Difference } \\
\text { between Groups }\end{array}$} \\
\hline & Pre & Post & $\begin{array}{c}\text { Change } \\
(\%)\end{array}$ & Sig. & $\eta^{2}$ & Pre & Post & $\begin{array}{c}\text { Change } \\
(\%)\end{array}$ & Sig. & $\eta^{2}$ & Sig. & $\eta^{2}$ \\
\hline Body mass (kg) & $79.5 \pm 12.8$ & $79.8 \pm 13.8$ & $0.23 \pm 2.1$ & 0.556 & 0.025 & $75.7 \pm 8.4$ & $76.5 \pm 7.8$ & $1.2 \pm 1.5$ & 0.120 & 0.160 & 0.308 & 0.074 \\
\hline Leg press 1-RM (kg) & $261.3 \pm 26.6$ & $312.5 \pm 18.32 *$ & $20.4 \pm 10.8$ & 0.000 & 0.835 & $237.5 \pm 30.5$ & $285.0 \pm 30.7 *$ & $20.4 \pm 5.9$ & 0.000 & 0.814 & 0.997 & 0.000 \\
\hline $\mathrm{RFD}_{30 \mathrm{~ms}}\left(\mathrm{~N} \cdot \mathrm{s}^{-1}\right)$ & $16,177 \pm 7400$ & $14,397 \pm 8383$ & $-3.3 \pm 14.5$ & 0.488 & 0.038 & $9242 \pm 4803$ & $11,384 \pm 2910$ & $43.6 \pm 56.8 \#$ & 0.358 & 0.065 & 0.016 & 0.350 \\
\hline $\operatorname{RFD}_{50 \mathrm{~ms}}\left(\mathrm{~N} \cdot \mathrm{s}^{-1}\right)$ & $18,299 \pm 5656$ & $16,587 \pm 7352$ & $-1.1 \pm 16.6$ & 0.796 & 0.005 & $11,345 \pm 5622$ & $14,320 \pm 4355$ & $44.3 \pm 58.9 \#$ & 0.376 & 0.061 & 0.023 & 0.323 \\
\hline $\operatorname{RFD}_{80 \mathrm{~ms}}\left(\mathrm{~N} \cdot \mathrm{s}^{-1}\right)$ & $18,227 \pm 3977$ & $17,411 \pm 5884$ & $-5.9 \pm 15.1$ & 0.899 & 0.001 & $12,587 \pm 5258$ & $15,378 \pm 4391$ & $33.4 \pm 47.3 \#$ & 0.329 & 0.073 & 0.042 & 0.263 \\
\hline $\mathrm{RFD}_{100 \mathrm{~ms}}\left(\mathrm{~N} \cdot \mathrm{s}^{-1}\right)$ & $17,257 \pm 3340$ & $17,030 \pm 5181$ & $-2.6 \pm 14.6$ & 0.760 & 0.007 & $12,611 \pm 4470$ & $15,041 \pm 4048$ & $26.4 \pm 39.2$ & 0.269 & 0.093 & 0.070 & 0.216 \\
\hline $\operatorname{RFD}_{150 \mathrm{~ms}}\left(\mathrm{~N} \cdot \mathrm{s}^{-1}\right)$ & $14,415 \pm 2451$ & $14,424 \pm 3438$ & $-0.7 \pm 10.4$ & 0.775 & 0.007 & $11,302 \pm 3084$ & $12,854 \pm 3124$ & $16.6 \pm 25.2$ & 0.188 & 0.129 & 0.095 & 0.186 \\
\hline $\mathrm{RFD}_{200 \mathrm{~ms}}\left(\mathrm{~N} \cdot \mathrm{s}^{-1}\right)$ & $11,985 \pm 1900$ & $12,240 \pm 2451$ & $1.9 \pm 10.6$ & 0.516 & 0.033 & $9746 \pm 2399$ & $10,691 \pm 2405$ & $11.5 \pm 19.4$ & 0.217 & 0.115 & 0.240 & 0.097 \\
\hline $\mathrm{RFD}_{250 \mathrm{~ms}}\left(\mathrm{~N} \cdot \mathrm{s}^{-1}\right)$ & $10,041 \pm 1480$ & $10,600 \pm 1933$ & $5.6 \pm 12.6$ & 0.150 & 0.153 & $8384 \pm 2050$ & $9146 \pm 1832$ & $11.3 \pm 18.4$ & 0.221 & 0.113 & 0.483 & 0.035 \\
\hline $\mathrm{IPF}(\mathrm{kgN})$ & $3119 \pm 529$ & $3498 \pm 628 *$ & $12.3 \pm 8.7$ & 0.001 & 0.547 & $2721 \pm 660$ & $3178 \pm 759 *$ & $17.4 \pm 8.5$ & 0.000 & 0.638 & 0.260 & 0.089 \\
\hline
\end{tabular}

$1-\mathrm{RM}=1$ Repetition Maximum, RFD = Rate of Force Development, IPF = Isometric Peak Force, ${ }^{*} p<0.05$, difference between Pre and Post measurements, \# $p<0.05$, difference between groups.

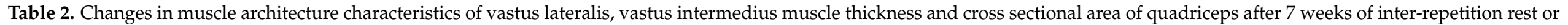
traditional resistance training.

\begin{tabular}{|c|c|c|c|c|c|c|c|c|c|c|c|c|}
\hline \multirow[b]{2}{*}{ Measurement } & \multicolumn{5}{|c|}{ Traditional Group } & \multicolumn{5}{|c|}{ Inter-Repetition Rest Group } & \multicolumn{2}{|c|}{$\begin{array}{c}\% \text { Difference } \\
\text { between Groups }\end{array}$} \\
\hline & Pre & Post & Change (\%) & Sig. & $\eta^{2}$ & Pre & Post & Change (\%) & Sig. & $\eta^{2}$ & Sig. & $\eta^{2}$ \\
\hline VL thickness (cm) & $2.6 \pm 0.4$ & $2.7 \pm 0.4^{*}$ & $4.8 \pm 7.5$ & 0.043 & 0.262 & $2.5 \pm 0.3$ & $2.6 \pm 0.2$ & $4.9 \pm 5.2$ & 0.048 & 0.260 & 0.983 & 0.000 \\
\hline VL length $(\mathrm{cm})$ & $8.7 \pm 1.6$ & $8.4 \pm 1.6$ & $-3.9 \pm 5.4$ & 0.078 & 0.205 & $8.3 \pm 0.9$ & $8.7 \pm 1.1$ * & $4.8 \pm 6.1 \#$ & 0.044 & 0.260 & 0.009 & 0.393 \\
\hline VL angle $\left({ }^{\circ}\right)$ & $19.1 \pm 1.7$ & $19.7 \pm 3.4$ & $3.1 \pm 10.7$ & 0.366 & 0.059 & $18.1 \pm 1.1$ & $18.1 \pm 1.5$ & $0.4 \pm 10.2$ & 0.983 & 0.000 & 0.618 & 0.018 \\
\hline VI thickness $(\mathrm{cm})$ & $2.1 \pm 0.3$ & $2.2 \pm 0.3$ & $1.3 \pm 11.3$ & 0.813 & 0.004 & $1.9 \pm 0.4$ & $2.1 \pm 0.4$ & $3.0 \pm 5.7$ & 0.442 & 0.043 & 0.711 & 0.000 \\
\hline $\begin{array}{l}\text { VL and VI Combined } \\
\text { Thickness }(\mathrm{cm})\end{array}$ & $4.7 \pm 0.5$ & $4.8 \pm 0.5^{*}$ & $3.2 \pm 4.0$ & 0.013 & 0.365 & $4.4 \pm 0.6$ & $4.6 \pm 0.5^{*}$ & $3.8 \pm 3.0$ & 0.010 & 0.387 & 0.735 & 0.000 \\
\hline VI CSA $\left(\mathrm{cm}^{2}\right)$ & $26.4 \pm 3.2$ & $29.5 \pm 3.1 *$ & $12.1 \pm 9.6$ & 0.013 & 0.367 & $26.5 \pm 5.7$ & $30.9 \pm 8.8 *$ & $15.7 \pm 9.6$ & 0.001 & 0.548 & 0.469 & 0.038 \\
\hline $\operatorname{RF} \operatorname{CSA}\left(\mathrm{cm}^{2}\right)$ & $9.6 \pm 1.6$ & $9.7 \pm 1.3$ & $0.8 \pm 4.8$ & 0.943 & 0.000 & $11.0 \pm 2.5$ & $11.7 \pm 3.6$ & $5.7 \pm 14.7$ & 0.104 & 0.177 & 0.393 & 0.053 \\
\hline $\operatorname{VM} C S A\left(\mathrm{~cm}^{2}\right)$ & $10.3 \pm 1.4$ & $12.3 \pm 1.7 *$ & $19.7 \pm 11.5$ & 0.003 & 0.468 & $11.6 \pm 3.3$ & $12.6 \pm 4.3$ & $7.8 \pm 18.2$ & 0.092 & 0.189 & 0.141 & 0.148 \\
\hline CSA Total $\left(\mathrm{cm}^{2}\right)$ & $65.2 \pm 7.8$ & $73.1 \pm 8.3 *$ & $12.5 \pm 7.6$ & 0.002 & 0.512 & $66.2 \pm 11.7$ & $76.0 \pm 16.6^{*}$ & $14.3 \pm 9.5$ & 0.000 & 0.611 & 0.690 & 0.012 \\
\hline
\end{tabular}

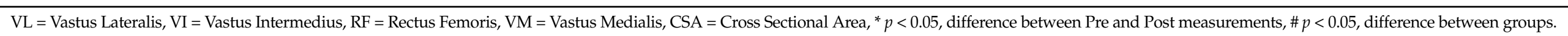




\section{Discussion}

The aim of the present study was to compare inter-repetition rest vs. traditional resistance training on lower body strength, RFD, VL muscle architecture, VI muscle thickness, and quadriceps CSA in active participants. The acute and chronic benefits of the cluster training method on muscle strength, power and velocity $[9,11-14]$ has led to the hypothesis that inter-repetition rest training would induce greater increases in RFD compared to traditional strength training. The main finding of the present study was that inter-repetition rest training lead to greater percentage increase of lower body RFD in contrast to traditional resistance training. Additionally, this finding was accompanied by a significant increase in VL fascicle length which was previously reported to increase after eccentric and strength-power training $[21,25,31]$. At the same time, inter-repetition rest resistance training increased strength, VL and VI thickness, and total quadriceps CSA, similarly to traditional resistance training. Consequently, increased VL fascicle length and lower body muscle hypertrophy after inter-repetition rest training may partially explain the greater percentage increases in RFD compared to traditional resistance training. These results suggest that $20 \mathrm{~s}$ of rest between single repetitions during heavy-load resistance training may enhance RFD and VL fascicle length besides increasing muscle mass.

Inter-repetition rest training induced significant percentage increases in 0-30 ms, 0-50 ms, and 0-80 ms RFD time frames compared to traditional training. Recently, Blazevich et al. [20], reported that RFD can be increased after resistance strength training when there is an intent for fast force production during training, even if the movement velocity lowers by the continued number of heavy load repetitions. In the present study, there was no specific direction to the participants to move the load fast. However, several studies have shown that inter-repetition rest resistance training increase the velocity of each repetition leading to a lower metabolic demand regardless of the directions provided to the participants $[4,9,10]$. RFD depends on several biological attributes, including type IIx fibres [19]. Traditional resistance training with several repetitions increases the metabolic demand of muscle fibers, which has been suggested to contribute to the type IIx to IIa muscle fibers transformation [42]. Training with inter-repetition rest induces lower metabolic demands on muscle fibers, which may suggest a smaller change of type IIx to IIa muscle fibers, which combined to increased type IIx fibers CSA would contribute to increased RFD. Unfortunately, it was not possible to obtain muscle biopsies in this study, which would have provided a better insight into the possible fiber type alterations in response to the two different training protocols used. Therefore, adding to the previous studies, the present results suggest that performing heavy load resistance training with $20 \mathrm{~s}$ of rest between repetitions favors the early phase of RFD compared to no-rest between repetitions and this may be achieved without the intention of fast force production. However, these results should be interpreted with caution due to the rarity of data on RFD changes in response to inter-repetition rest training.

Both 1-RM leg press and isometric PF were similarly increased after inter-repetition rest and traditional resistance training. This finding is in agreement with the findings of Iglesias-Soler et al. [17], where five weeks of either traditional resistance training or interrepetition rest training re-distributing the total rest period between repetitions and sets, induced the same increases in 1-RM strength. However, there is a controversy among studies on this issue. Some studies revealed a greater increase in muscle strength after cluster resistance training $[4,13]$. Additionally, other studies showed a greater improvement in muscle strength following traditional resistance training $[15,16]$. These conflicting results may be due to the different training background of the participants and/or the simultaneous training of other body parts which may have resulted in different neural adaptations [18] and as a consequence different strength adaptations. In the present study, training volume and RPE were similar between IRRG and TG, suggesting that both groups experienced similar subjective exertion. This may partially explain the similar increases in muscle strength after both training programs. 
Inter-repetition rest resistance training induced greater increases in VL fascicle length compared to traditional resistance training. It has been suggested that increases in fascicle length indicate increases in the number of sarcomeres in series which in turn contribute to higher shortening velocity and intrinsic muscle power, especially in response to eccentric and strength-power training $[25,43]$. The key difference between the inter-repetition rest and traditional resistance training is the rest between repetitions [7]. This training parameter may result in lower metabolic stress during a cluster set compared to a traditional set [8]. To our knowledge no data has linked metabolic stress and fascicle length, therefore the current higher response of the VL fascicle length in response to inter-repetition rest training is difficult to interpret. Thus, changes in fascicle length after inter-repetition rest resistance training needs further investigation.

Increases in lower body 1-RM strength and isometric PF were accompanied by increases in quadriceps CSA and thickness of VL and VI, in both groups. In line with these results, Oliver et al. [13], showed that cluster training induced similar hypertrophic adaptations to traditional training after 12 weeks. Muscle hypertrophy, as measured here with muscle ultrasonography, is mainly depending on training volume [44]. In the current study, both groups trained with similar training volumes performing the same number of sets and repetitions. Thus, the inclusion of $20 \mathrm{~s}$ inter-repetition rest did not result in greater training volume or muscle hypertrophy which could have increased the hypertrophic result [7] compared to traditional resistance training.

To our knowledge, this is the first study evaluating changes in RFD and muscle architecture following inter-repetition rest compared to traditional resistance training; thus, the results of this study should be interpreted with a certain degree of caution. A longer training period might have induced stronger changes in RFD and muscle architecture which would probably illustrate better the degree of these adaptations in response to inter-repetition rest training. Moreover, increases in early RFD are linked with increased neural input and the percentage CSA of type II muscle fibers. Unfortunately, neither electromyographic data nor muscle biopsies were obtained in the current study which would have increased our understanding of the underlying physiological adaptations to this type of training. Another limitation of the current study was the relatively small number of participants in both training groups. As a final point, resistance training was performed without the intention to produce maximum velocity during the concentric phase. Future studies may address these issues and provide a more detailed assessment of the effectiveness of the inter-repetition rest resistance training using maximum velocity during the concentric phase.

\section{Conclusions}

In conclusion, the novel findings of the current study suggest that inter-repetition rest resistance training configuration increases early RFD and VL fascicle length compared to traditional resistance training after seven weeks training. Inter-repetition rest training induced increases in both dynamic and isometric strength as well as muscle hypertrophy, which were similar to the traditional resistance training. Therefore, inter-repetition rest resistance training with single repetitions and $20 \mathrm{~s}$ rest between repetitions can be effectively used for enhancing lower body muscular explosive strength and muscle hypertrophy. Thus, strength and conditioning coaches may effectively use inter-repetition rest resistance training in order to increase lower body maximum strength without limiting explosive power performance. Seven weeks of inter-repetition rest resistance training can be effectively used during a high load mesocycle aiming to develop both maximum strength and hypertrophy while maintaining the explosiveness of athletes. Consequently, inter-repetition rest resistance training can be effective for sports characterized by shorttime muscle contractions (i.e., sprinters, jumpers, and throwers) and explosive power performance demands. 
Author Contributions: N.Z. designed the experiment, collected the data, analyzed the data, and wrote the manuscript. A.-N.S. collected the data and analyzed the data. P.S. collected the data and analyzed the data. T.M. collected the data and analyzes the data. M.H. analyzes the data and wrote the manuscript. G.T. designed the experiment and wrote the manuscript. All authors have read and agreed to the published version of the manuscript.

Funding: This research received no external funding.

Data Availability Statement: The data presented in this study are available on request from the corresponding author.

Acknowledgments: Authors express their gratitude to the participants of the study. Authors also thank Anastasia Georgaki and Michalis Vogiatzoglou for their assistance during the training period. No funding was received for the study and there was no conflict of interest from the results of this study.

Conflicts of Interest: The authors declare no conflict of interest.

\section{References}

1. Thomas, H.M.; Burns, P.S. Increasing Lean Mass and Strength: A comparison of high frequency strength training to lower frequency strength training. Int. J. Exers. Sci. 2016, 9, 159-167.

2. Counts, R.B.; Buckner, L.S.; Mouser, J.G.; Dankel, J.S.; Jessee, B.M.; Mattocks, T.K.; Loenneke, J.P. Muscle growth: To infinity and beyond? Muscle Nerve 2017, 56, 1022-1030. [CrossRef]

3. Iglesias-Soler, E.; Carballeira, E.; Sanchez-Otero, T.; Mayo, X.; Jimenez, A.; Chapman, M.L. Acute effects of distribution of rest between repetitions. Int. J. Sports Med. 2012, 33, 351-358. [CrossRef]

4. Nicholson, G.; Ispoglou, T.; Bissas, A. The impact of repetition mechanics on the adaptations resulting from strength-, hypertrophyand cluster-type resistance training. Eur. J. Appl. Physiol. 2016, 116, 1875-1888. [CrossRef]

5. Gorostiaga, E.M.; Navarro-Amèzqueta, I.; Calbet, J.A.L.; Sánchez-Medina, L.; Cusso, R.; Guerrero, M.; Granados, C.; GonzálezIzal, M.; Ibáñez, J.; Izquierdo, M. Blood ammonia and lactate as markers of muscle metabolites during leg press exercise. J. Strength Cond. Res. 2014, 28, 2775-2785. [CrossRef] [PubMed]

6. Taylor, J.L.; Amann, M.; Duchateau, J.; Meeusen, R.; Rice, C.L. Neural Contributions to Muscle Fatigue: From the Brain to the Muscle and Back Again. Med. Sci. Sports Exerc. 2016, 48, 2294-2306. [CrossRef] [PubMed]

7. Tufano, J.J.; Brown, L.E.; Haff, G.G. Theoretical and practical aspects of different cluster set structures: A systematic review. J. Strength Cond. Res. 2017, 31, 848-867. [CrossRef] [PubMed]

8. Haff, G.G.; Hobbs, R.T.; Haff, E.E.; Sands, W.A.; Pierce, K.C.; Stone, M.H. Cluster training: A novel method for introducing training program variation. Strength Cond. J. 2008, 30, 67-76. [CrossRef]

9. Mora-Custodio, R.; Rodríguez-Rosell, D.; Yáñez-García, J.M.; Sánchez-Moreno, M.; Pareja-Blanco, F.; González-Badillo, J.J. Effect of different inter-repetition rest intervals across four load intensities on velocity loss and blood lactate concentration during full squat exercise. J. Sports Sci. 2018, 36, 2856-2864. [CrossRef] [PubMed]

10. Rial-Vázquez, J.; Mayo, X.; Tufano, J.J.; Fariñas, J.; Rúa-Alonso, M.; Iglesias-Soler, E. Cluster vs. traditional training programs: Changes in the force-velocity relationship. Sports Biomech. 2020, 5, 1-19. [CrossRef]

11. Iglesias, E.; Boullosa, D.A.; Dopico, X.; Carballeira, E. Analysis of factors that influence the maximum number of repetitions in two upper-body resistance exercises: Curl biceps and bench press. J. Strength Cond. Res. 2010, 24, 1566-1572. [CrossRef] [PubMed]

12. Iglesias-Soler, E.; Carballeira, E.; Sanchez-Otero, T.; Mayo, X.; Fernandez-Del-Olmo, M. Performance of maximum number of repetitions with cluster set configuration. Int. J. Sports Physiol. Perf. 2014, 9, 637-642. [CrossRef] [PubMed]

13. Oliver, J.M.; Jagim, A.R.; Sanchez, A.C.; Mardock, M.A.; Kelly, K.A.; Meredith, H.J.; Smith, G.L.; Greenwood, M.; Parker, J.L.; Riechman, S.E.; et al. Greater gains in strength and power with intraset rest intervals in hypertrophic training. J. Strength Cond. Res. 2013, 27, 3116-3131. [CrossRef] [PubMed]

14. Oliver, J.M.; Kreutzer, A.; Jenke, S.; Phillips, M.D.; Mitchell, J.B.; Jones, M.T. Acute response to cluster sets in trained and untrained men. Eur. J. Appl. Physiol. 2015, 15, 2383-2393. [CrossRef]

15. Hansen, K.T.; Cronin, J.B.; Pickering, S.L.; Newton, M.J. Does cluster loading enhance lower body power development in preseason preparation of elite rugby union players? J. Strength Cond. Res. 2011, 25, 2118-2126. [CrossRef]

16. Zarezadeh-Mehrizi, A.; Aminai, M.; Amiri-khorasani, M. Effects of traditional and cluster resistance training on explosive power in soccer players. Iranian J. Health Phys. Act. 2013, 4, 51-56.

17. Iglesias-Soler, E.; Mayo, X.; Río-Rodríguez, D.; Carballeira, E.; Fariñas, F.; Fernández-Del-Olmo, F. Inter-repetition rest training and traditional set configuration produce similar strength gains without cortical adaptations. J. Sports Sci. 2015, 34, 1473-1484. [CrossRef]

18. Sale, D.G. Neural Adaptations to Strength Training. In Strength and Power in Sport, 2nd ed.; Komi, P.V., Ed.; Blackwell Science Ltd.: Oxford, UK, 2003; pp. 281-314.

19. Maffiuletti, N.A.; Aagaard, P.; Blazevich, A.J.; Folland, J.; Tillin, N.; Duchateau, J. Rate of force development: Physiological and methodological considerations. Eur. J. Appl. Physiol. 2016, 116, 1091-1116. [CrossRef] 
20. Blazevich, A.J.; Wilson, C.J.; Alcaraz, P.E.; Rubio-Arias, J.A. Effects of Resistance Training Movement Pattern and Velocity on Isometric Muscular Rate of Force Development: A Systematic Review with Meta-analysis and Meta-regression. Sports Med. 2020, 50, 943-963. [CrossRef]

21. Zaras, N.D.; Stasinaki, A.-N.E.; Methenitis, S.K.; Krase, A.A.; Karampatsos, G.P.; Georgiadis, G.V.; Terzis, G. Rate of force development, muscle architecture, and performance in young competitive track and field throwers. J. Strength Cond. Res. 2016, 30, 81-92. [CrossRef]

22. Zaras, N.D.; Stasinaki, A.-N.E.; Krase, A.A.; Methenitis, S.K.; Karampatsos, G.P.; Georgiadis, G.V.; Spengos, K.M.; Terzis, G.D. Effects of tapering with light vs. heavy loads on track and field throwing performance. J. Strength Cond. Res. 2014, 28, 3484-3495. [CrossRef]

23. Davies, T.B.; Halaki, M.; Orr, R.; Helms, E.R.; Hackett, D.A. Changes in bench press velocity and power after 8 weeks of high-load cluster or traditional-set structures. J. Strength Cond. Res. 2019, 34, 2734-2742. [CrossRef] [PubMed]

24. Ruiz-Cárdenasa, J.D.; Rodríguez-Juana, J.J.; Ríos-Díaza, J. Relationship between jumping abilities and skeletal muscle architecture of lower limbs in humans: Systematic review and meta-analysis. Hum. Mov. Sci. 2018, 58, 10-20. [CrossRef] [PubMed]

25. Stasinaki, A.-N.; Zaras, N.; Methenitis, S.; Bogdanis, G.; Terzis, G. Rate of force, development and muscle architecture after fast and slow velocity eccentric training. Sports 2019, 7, 41. [CrossRef] [PubMed]

26. Zaras, N.; Stasinaki, A.-N.; Methenitis, S.K.; Karampatsos, G.P.; Fatouros, I.; Hadjicharalambous, M.; Terzis, G. Track and field throwing performance prediction: Training intervention, muscle architecture adaptations and field tests explosiveness ability. J. Phys. Educ. Sport. 2019, 19, 436-443. [CrossRef]

27. Aagaard, P.; Andersen, L.J.; Dyhre-Poulsen, P.; Leffers, M.A.; Wagner, A.; Magnusson, P.S.; Kristensen, H.J.; Simonsen, B.E. A mechanism for increase contractile strength of human pennate muscle in response to strength training: Changes in muscle architecture. J. Physiol. 2001, 534, 613-623. [CrossRef] [PubMed]

28. Cormie, P.; McGuigan, M.R.; Newton, R.U. Adaptations in athletic performance after ballistic power versus strength training. Med. Sci. Sports Exerc. 2010, 42, 1582-1598. [CrossRef]

29. Stasinaki, A.-N.; Gloumis, G.; Spengos, K.; Blazevich, A.J.; Zaras, N.; Georgiadis, G.; Karampatsos, G.; Terzis, G. Muscle strength, power, and morphologic adaptations after 6 weeks of compound vs. complex training in healthy men. J. Strength Cond. Res. 2015, 29, 2559-2569. [CrossRef]

30. Alonso-Fernandez, D.; Docampo-Blanco, P.; Martinez-Fernandez, J. Changes in muscle architecture of biceps femoris induced by eccentric strength training with nordic hamstring exercise. Scand. J. Med. Sci. Sports 2018, 28, 88-94. [CrossRef]

31. Zacharia, E.; Spiliopoulou, P.; Methenitis, S.; Stasinaki, A.-N.; Zaras, N.; Papadopoulos, C.; Papadimas, G.; Karampatsos, G.; Bogdanis, G.; Terzis, G. Changes in muscle power and muscle morphology with different volumes of fast eccentric half-squats. Sports 2019, 7, 164. [CrossRef]

32. Hardee, J.P.; Triplett, N.T.; Utter, A.C.; Zwetsloot, K.A.; Mcbride, J.M. Effect of interrepetition rest on power output in the power clean. J. Strength Cond. Res. 2012, 26, 883-889. [CrossRef] [PubMed]

33. Borg, G.A. Psychophysical bases of perceived exertion. Med. Sci. Sports Exerc. 1982, 5, 377-381. [CrossRef]

34. Day, M.L.; McGuigan, M.R.; Brice, G.; Foster, C. Monitoring exercise intensity during resistance training using the session RPE scale. J. Strength Cond. Res. 2004, 18, 353-358. [CrossRef]

35. Sweet, T.W.; Foster, C.; McGuigan, M.R.; Brice, G. Quantitation of resistance training using the session rating of perceived exertion method. J. Strength Cond. Res. 2004, 18, 796-802. [CrossRef] [PubMed]

36. Zaras, N.; Stasinaki, A.N.; Spiliopoulou, P.; Arnaoutis, G.; Hantjicharalambous, M.; Terzis, G. Rate of force development, muscle architecture and performance in elite weightlifters. Inter. J. Sports Phys. Perf. 2020. Ahead of Print. [CrossRef]

37. Aagaard, P.; Simonsen, E.B.; Andersen, J.L.; Magnusson, P.; Duhre-Poulsen, P. Increase rate of force development and neural drive of human skeletal muscle following resistance training. J. Appl. Physiol. 2002, 93, 1318-1326. [CrossRef]

38. Blazevich, A.J.; Gill, N.D.; Zhou, S. Intra- and intermuscular variation in human quadriceps femoris architecture assessed in vivo. J. Anat. 2006, 209, 289-310. [CrossRef]

39. Tsitkanou, S.; Spengos, K.; Stasinaki, A.-N.; Zaras, N.; Bogdanis, G.; Papadimas, G.; Terzis, G. Effects of high-intensity interval cycling performed after resistance training on muscle strength and hypertrophy. Scand. J. Med. Sci. Sports 2017, 27, 1317-1327. [CrossRef]

40. Noorkoiv, M.; Stavnsbo, A.; Aagaard, P.; Blazevich, A. In Vivo assessment of muscle fascicle length by extended field-of-view ultrasonography. J. Appl. Physiol. 2010, 109, 1974-1979. [CrossRef]

41. Noorkoiv, M.; Nosaka, K.; Blazevich, A.J. Assessment of quadriceps muscle cross-section area by ultrasound extended-field-ofview imaging. Eur. J. Appl. Physiol. 2010, 109, 631-639. [CrossRef]

42. Andersen, L.J.; Aagaard, P. Myosin heavy chain IIX overshoot in human skeletal muscle. Muscle Nerve 2000, $23,1095-1104$. [CrossRef]

43. Blazevich, A.J.; Cannavan, D.; Coleman, D.R.; Horne, S. Influence of concentric and eccentric resistance training on architectural adaptation in human quadriceps muscles. J. Appl. Physiol. 2007, 103, 1565-1575. [CrossRef] [PubMed]

44. Schoenfeld, B.J.; Ogborn, D.; Krieger, J.W. Dose response relationship between weekly resistance training volume and increases in muscle mass: A systematic review and meta-analysis. J. Sports Sci. 2016, 35, 1079-1082. [CrossRef] [PubMed] 